\title{
Absorption of glucose from urinary conduits in diabetics and non-diabetics
}

\author{
K N SRIDHAR, C T SAMUELL, C R J WOODHOUSE
}

\begin{abstract}
The ability of urinary conduits to absorb glucose was investigated. A solution containing $1 \%$ glucose and the inert marker phenol red was put into conduits in diabetic and non-diabetic patients. Samples were withdrawn at intervals for analysis and the fall in concentrations plotted against time. The loops in the patients without diabetes did not absorb glucose, but glucose was absorbed in one of the three diabetics.

Ileal loops in patients with diabetes may absorb urinary glucose. This should be checked in any diabetic with urinary diversion before advice is given on long term management. Routine testing of conduit urine for glucose may not be an adequate screen for diabetes in patients with urinary diversions.
\end{abstract}

\section{Introduction}

Among the metabolic abnormalities that have been reported after urinary diversion by intestinal conduit is the absence of glycosuria in diabetics. ${ }^{1}$ This phenomenon was emphasised by a report on a patient with unrecognised diabetes who developed severe ketoacidosis without glucose appearing in the urine in his ileal loop. ${ }^{2}$ This observation may be explained in two ways: either the conduit absorbs the urinary glucose or the urinary bacteria present in some cases metabolise the glucose.

We developed techniques to investigate these possibilities. The principal method depends on comparing the concentrations of glucose and an inert marker, phenol red, in a test solution.

\footnotetext{
Academic Unit and Department of Biochemistry, Institute of Urology and St Peter's Hospitals, London WC2H 8JE

K N SRIDHAR, MB, FRCS, lecturer in urology

C T SAMUELL, MIBIOL, MCB, principal biochemist

C R J WOODHOUSE, MB, FRCS, senior lecturer and honorary consultant urologist

Correspondence to: Mr C R J Woodhouse.
}

If phenol red is put into the whole intestine considerable amounts are absorbed, but in segments of intestine up to $100 \mathrm{~cm}$ long insignificant amounts are absorbed. ${ }^{34}$ The validity of this marker has been confirmed by comparison with another non-absorbed substance, macrogol, in short segments of normal and diseased intestine. ${ }^{5}$ If a solution of marker and glucose is put into a conduit both will be diluted equally by urine or osmotic influx. If glucose is absorbed its concentration will fall faster than that of the marker.

\section{Patients and methods}

We studied two groups of patients. One group consisted of seven volunteer patients with non-obstructed urinary conduits that had been present for at least one year (four ileal and three colonic) who had no diabetes on the basis of normal random blood glucose concentrations $(<4.7 \mathrm{mmol} / \mathrm{l}(<85 \mathrm{mg} / 100 \mathrm{ml}))$. The other group consisted of three diabetics with ileal conduits (one with insulin dependent diabetes, one non-insulin dependent diabetes, and one with mild diabetes controlled by diet alone). We attempted to find more diabetic patients by canvassing 26 stoma therapists in the London area but were unsuccessful.

The patients were not fasted, and diabetic medication was maintained. With the patients supine a 14 French gauge Foley catheter was introduced as far as possible into the urinary stoma. Residual urine was removed by gentle suction as the catheter was withdrawn: aliquots were examined microscopically and cultured in the conventional way. The conduit was then filled with physiological saline several times to measure its volume and wash out surplus mucus. The balloon of the catheter was inflated sufficiently to occlude the stoma completely, and any residual saline was drained.

A prepared solution of $1 \%$ glucose in half physiological saline with $0.001 \%$ phenol red as an inert, non-absorbed marker was used. The conduit was filled with this test solution; the catheter was clamped and gentle upward traction applied to prevent stomal leakage (fig 1). Fluid $(1 \mathrm{ml})$ was withdrawn from the conduit at intervals (beginning after five minutes). The experiment was stopped after 60 minutes or when leakage around the Foley balloon occurred (in most cases after 30 minutes). The specimens from the conduits were collected into standard fluoride and oxalate tubes and, unless analysed immediately, were stored at $-20^{\circ} \mathrm{C}$. All specimens were centrifuged before analysis to remove debris. Phenol red concentration was assayed spectrophotometrically by the technique described by McLeod et al. ${ }^{3}$ Glucose concentration was measured enzymatically with an Analox 
GM6 oxidase analyser (Alpha Laboratories, Eastleigh, Hampshire). Because enzymatic glucose assays can be inhibited by urinary constituents recovery of glucose added to the urine was checked and found to be satisfactory. The results were plotted as a graph showing the fall in concentrations of phenol red and glucose (expressed as a percentage of the original concentration) against time.

It is conceivable that urinary bacteria metabolise sufficient glucose to reduce the glucose concentration. Therefore, glucose was added to infected urine to achieve a final concentration of $20 \mathrm{mmol} / 1(360 \mathrm{mg} /$ $100 \mathrm{ml}$ ) and incubated at $37^{\circ} \mathrm{C}$ for one hour. The bacteria used were Streptococcus faecalis, Escherichia coli, Proteus mirabilis, Klebsiella pneumoniae, and Pseudomonas pyocyneus.

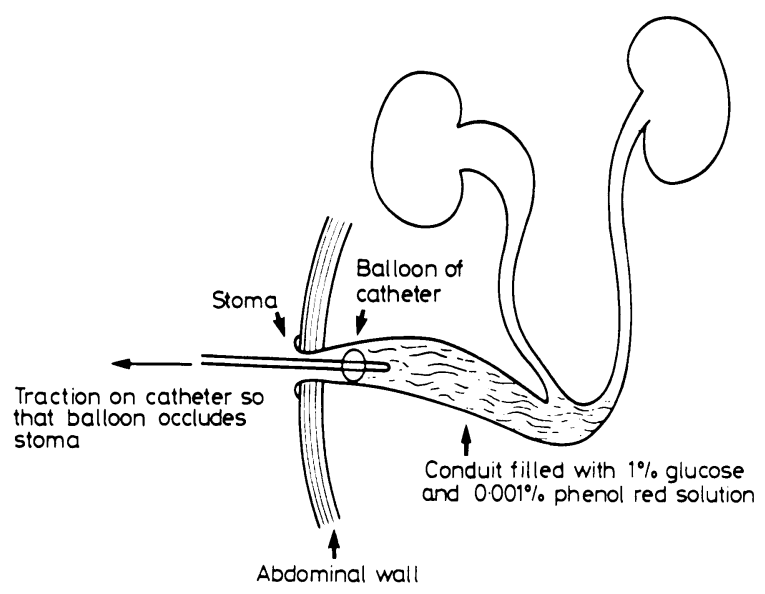

FIG 1-Diagram of a urinary conduit, showing investigation technique.

\section{Results}

The capacity of the loops in the seven patients without diabetes ranged from $15 \mathrm{ml}$ to $60 \mathrm{ml}$ (average $34 \mathrm{ml}$ ). In six of these volunteers the concentrations of phenol red and glucose in the solution collected from the conduit fell at the same rate (fig 2). In the seventh patient, who had a colonic conduit, the concentration of phenol red fell more steeply than that of glucose (case 10, fig 2). We believe that this was due to the binding of phenol red to excessive mucus that was noted in the loop, a phenomenon that has been reported in gastrointestinal mucosa. ${ }^{3}$

None of the three diabetics had glycosuria before the study even though one patient (case 3) had a blood glucose concentration of $12.3 \mathrm{mmol} / 1(222 \mathrm{mg} / 100 \mathrm{ml})$. The table shows the clinical details. In two patients the concentrations of glucose and phenol red fell at the same rate, just as in the non-diabetic patients. In the remaining patient (case 3) the concentration of glucose fell more steeply, suggesting that some was being absorbed by the mucosa of the ileal loop.

When urinary bacteria were incubated in the glucose solution for one hour the concentration of glucose did not change in any specimen.

\section{Discussion}

Various metabolic disturbances have been described and investigated in patients with urinary diversions. When the diversion is via a short intestinal conduit to an abdominal wall
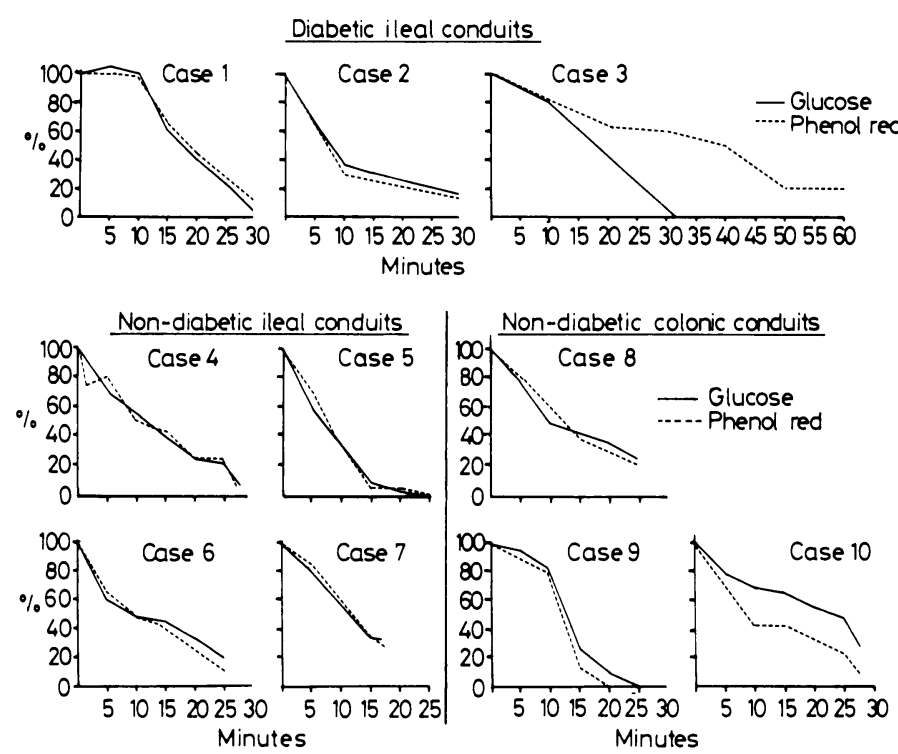

FIG 2-Concentrations of glucose and phenol red in each patient as percentage of original concentrations in test solution.

stoma clinical metabolic problems are rare. If loop urine does not contain glucose in diabetes this would have serious im- N plications in the small number of diabetics requiring diversion $O$ and in patients with a diversion who subsequently develop $\stackrel{c}{o}$ diabetes. The renal threshold in a patient with glycosuria is $Z$ unlikely to be altered by diversion provided that renal function remains substantially normal. Therefore, glucose excreted in the urine would disappear only if it was absorbed or metabolised in the conduit itself. To investigate this we did not believe that existing experimental methods, designed for urinary $\vec{\varphi}$ electrolytes, would be suitable. ${ }^{7}$ Likewise, methods for investigating absorption of glucose from the intact gastrointestinal tract were of no use. ${ }^{8}{ }^{9}$ The experimental method that we used was developed from the one described by Dretler, ${ }^{10}$ with phenol red being used as an inert marker.

If ileum in the conduit behaved in the same way as "gastrointestinal" ileum some absorption of glucose could be expected, $\stackrel{\varrho}{\Rightarrow}$ especially in a diabetic and in the presence of sodium ions. ${ }^{4} \overrightarrow{0}$ Similarly, intact gastrointestinal colon can absorb large quantities of glucose. ${ }^{9}$ Urine flowing through a conduit, however, may not be in contact with mucosa for a sufficient time for changes in glucose concentration to occur. Insulin is thought not to influence absorption of glucose. ${ }^{11}$

We found that, under these experimental conditions, there is no appreciable absorption or metabolism of glucose by either ileal or colonic conduits in non-diabetic patients. This supports $\delta$ the results of Baker et al, who found no absorption of glucose in $₹$ the terminal $10 \mathrm{~cm}$ of ileum of the rat. ${ }^{12}$ In one of the three $\frac{0}{2}$ diabetics there was evidence that glucose was absorbed by the $N$ ileal conduit: glucose was not detectable in the loop contents of after 30 minutes. This patient was aware that she did not have $\frac{D}{0}$ glycosuria and controlled her diabetes with serial blood glucose estimations. At the time of the experiment she had a blood $\tilde{N}$ glucose concentration of $12.3 \mathrm{mmol} / 1(222 \mathrm{mg} / 100 \mathrm{ml})$ and no glycosuria. Her loop was a little large at $70 \mathrm{ml}$ but was not

Clinical details of diabetic patients with ileal conduit urinary diversions

\begin{tabular}{|c|c|c|c|c|c|c|c|c|}
\hline \multirow{2}{*}{ Case No } & \multirow{2}{*}{ Sex } & \multirow{2}{*}{$\begin{array}{c}\text { Age } \\
\text { (years) }\end{array}$} & \multirow{2}{*}{ Type of diabetes } & \multirow{2}{*}{ Treatment } & \multirow{2}{*}{ Diabetic problems } & \multirow{2}{*}{$\begin{array}{l}\text { Blood glucose at } \\
\text { start of experiment } \\
(\mathrm{mmol} / 1)\end{array}$} & \multicolumn{2}{|c|}{ Glycosuria* } \\
\hline & & & & & & & Before diversion & After diversion \\
\hline $\begin{array}{l}1 \\
2 \\
3\end{array}$ & $\begin{array}{l}\mathrm{M} \\
\mathrm{M} \\
\mathrm{F}\end{array}$ & $\begin{array}{l}55 \\
62 \\
70\end{array}$ & $\begin{array}{l}\text { Non-insulin dependent } \\
\text { Mild, controlled with diet } \\
\text { Insulin dependent }\end{array}$ & $\begin{array}{l}\text { Oral agents } \\
\text { Diet } \\
\text { Soluble insulin }\end{array}$ & $\begin{array}{l}\text { Ketoacidosis on one occasion } \\
\text { None } \\
\text { None }\end{array}$ & $\begin{array}{r}7 \cdot 0 \\
6 \cdot 1 \\
12 \cdot 3\end{array}$ & $\begin{array}{l}\text { Yest } \\
\text { Yes } \\
\text { Yes }\end{array}$ & $\begin{array}{l}\text { No } \\
\text { No } \\
\text { No }\end{array}$ \\
\hline
\end{tabular}


obstructed, having a residual of $5 \mathrm{ml}$ urine. Diabetes had been diagnosed before her diversion, and she had had glycosuria in her bladder urine. One of the diabetic patients (case 1) had been reported on previously ${ }^{2}$ and had had ketoacidosis without glycosuria. He did not have conduit glycosuria on any other occasion (though this may reflect good diabetic control). Under the conditions of this experiment, however, his loop did not remove glucose and it is therefore difficult to explain how this clinical problem arose. Glycosuria had been noted on two occasions before diversion, suggesting that he had a normal renal threshold for glucose. It is possible that during ketoacidosis, altered urinary ionic concentrations secondary to poor renal function enhanced reabsorption of glucose or raised the renal threshold. ${ }^{413}$

The ability of a conduit to absorb glucose would depend in part on the integrity of its mucosa. We did not obtain biopsy samples of these loops, but in a series of excised loops we consistently found mucosal atrophy (paper in preparation). Interestingly, both cases described by McGournan occurred early after diversion, perhaps before any metaplasia had occurred in the conduit mucosa. ${ }^{1}$

In this experiment we looked only at absorption of glucose under one set of conditions (albeit reasonably physiological ones). Further study with other ions in the solution is needed to understand fully the problems of the diabetic urinary conduit. On the basis of our work so far we conclude that urinary conduits in non-diabetic patients do not absorb glucose. In diabetics it is possible that sufficient glucose may be absorbed to abolish glycosuria: this point should be checked in individual patients before advice is given on routine diabetic management. When screening patients with diversion for diabetes random measurement of blood glucose concentrations must be performed. The method that we have described would be suitable for the study of other conduit urine constituents.
We are grateful to Dr D F Evered, of Chelsea College, and to Dr G A Nelstrop, consultant physician, for their advice and help. Mrs A Stainton kindly prepared the glucose and phenol red solutions.

\section{References}

${ }^{1}$ McGournan RCM. Glucose absorption from ileal loops. $\mathrm{Br}$ Med $\mathcal{F}$ 1977; ii :932.

${ }^{2}$ Onwubalili JK. Overt diabetes mellitus without glycosuria in a patient with cutaneous ureteroiliostomy. $\mathrm{Br} M$ Med $\mathcal{F} 1982 ; 284: 1836$.

${ }^{3}$ McLeod GM, French AB, Good CJ, Wright FS. Gastrointestinal absorption and biliary excretion of phenol red in man. $f \mathrm{Lab}$ Clin Med 1968;71:192-5.

${ }^{4}$ Modigliani R, Rambaud JC, Bernier JJ. Method of intraluminal perfusion of the human small intestine. Digestion 1973;9:176-92.

${ }^{5}$ French AB, Brown IF, Good CJ, McLeod GM. Comparison of phenol red and polyethylene glycol as non-absorbable markers for the study of intestinal absorption in humans. Am 7 Dig Dis 1968;13:558-64.

6 Janknegt RA. Absorption of urine in jejunum, ileum and sigmoid loops. Urol Int 1967;22:435-45.

7 Demos MP. Radioactive electrolyte absorption studies of small bowel: comparison of different segments for use in urinary diversion. $\mathcal{F}$ Urol $1962 ; 88: 638-43$.

${ }^{8}$ Davidson JN, Garry RK. The absorption of monosaccharides from the large intestine of the rat under urethane anaesthetic. $\mathcal{F}$ Physiol (Lond) $1939 ; 96: 172-5$.

${ }^{9}$ Curry FS, Bargen JA. Studies on absorption and excretion in segments of the colon of man. Surg Gynecol Obstet 1935;60:667-74.

${ }^{10}$ Dretler SP. The pathogenesis of urinary tract calculi occurring after ileal conduit diversion. I. Clinical study. II. Conduit study. III. Prevention. f Urol 1973;109:204-9.

${ }^{11}$ Ganong WF. Digestion and absorbtion. In: Ganong WF, ed. Review of medical physiology. 8th ed. California: Lange Medical, 1977:352-9.

12 Baker RA, Searle GW, Nunn AS. Glucose and sorbose absorption at various levels of rat small intestine. Am F Physiol 1961;200:301-3.

${ }^{13}$ Manning AS, McMullan JM, Evered DF. Influence of calcium ions on uptake of sugars by rat small intestine in vitro. Biochem Soc Trans $1978 ; 6: 914-6$.

(Accepted 24 August 1983)

\title{
Hyposensitisation to wasp venom in six hours
}

\author{
J C VAN DER ZWAN, J FLINTERMAN， I G JANKOWSKI，J A M KERCKHAERT
}

\begin{abstract}
Eleven patients with a history of anaphylaxis, positive reactions to skin tests, and specific IgE antibody to wasp venom underwent hyposensitisation in a six hour procedure. No general reactions occurred. Complement activation and proteinuria could not be shown.

The patterns of specific IgE, IgG1, and IgG4 were as described in other procedures-namely, IgE increased sharply and then decreased; IgG1 and IgG4 increased steadily and then decreased-but increase and decrease came earlier.

Challenge by a stinging insect at least four weeks after treatment proved complete protection. The skin reactivity two years later showed an unpredictable pattern.
\end{abstract}

\section{Introduction}

Anaphylaxis to venom by insects of the order Hymenoptera is common and leads to several deaths each year. ${ }^{1}$ Fear of fatal reactions and a consequent change in lifestyle follows non-fatal systemic reaction to the venom. ${ }^{2}$ Since the first procedure of hyposensitisation with pure venom was described in $1974,{ }^{3}$ details of many different methods have been published. ${ }^{4-7}$ Insect venoms and venom proteins have been used in the diagnosis of insect sting allergy by direct skin testing. ${ }^{4}$ Analysis by means of the radioallergosorbent test for specific IgE antibody has been performed. ${ }^{8}$

We studied 11 patients at risk of developing anaphylaxis to wasp venom. Hyposensitisation with the maximum dose was achieved within six hours. Complement activation as well as proteinuria were looked for. The different titres of total IgE and specific IgE, IgG1, and IgG4 against wasp venom were studied over seven months.

\section{Patients and methods}

Ten women and one man fulfilled the criteria suggested by Lichtenstein ${ }^{9}$ : an early general reaction, positive reaction to skin test with wasp venom, and the presence of specific IgE in the serum
J FLINTERMAN, MD, dermatologist

J A M KERCKHAERT, MD, immunologist 